\title{
Limb fracture during recovery from general anaesthesia: an often tragic complication of equine anaesthesia
}

\author{
T B Dzikiti ${ }^{a^{*}}$, L Bester $^{\mathrm{a}}$, I Cilliers ${ }^{\mathrm{a}}$, A Carstens $^{\mathrm{a}}$, G F Stegmann ${ }^{\mathrm{a}}$ and J Hubert ${ }^{\mathrm{a}}$
}

\begin{abstract}
A 10-year-old Thoroughbred mare was presented for lameness of the left hindlimb as a result of an apical fracture of the lateral proximal sesamoid bone. The mare was ultimately euthanased after suffering catastrophic fractures of the 3rd and 4th metatarsal bones of the contra-lateral hindlimb during an uncoordinated attempt to rise during recovery from general anaesthesia after undergoing arthroscopic surgery. The case report focuses mostly on horse anaesthesia-related mortality, anaesthetic procedure in the horse, possible causes of fractures in horses during recovery and ways in which rate of occurrence of these fractures can be minimised.

Key words: equine, anaesthetic mortality, recovery.

Dzikiti T B, Bester L, Cilliers I, Carstens A, Stegmann G F, Hubert J Limb fracture during recovery from general anaesthesia: an often tragic complication of equine anaesthesia. Journal of the South African Veterinary Association (2008) 79(3): 145-148 (En.). Department of Companion Animal Clinical Studies, Faculty of Veterinary Science, University of Pretoria, Private Bag X04, Ondesterpoort, 0110 South Africa
\end{abstract}

\section{INTRODUCTION}

Ever since the advent of anaesthesia in 1846 , the subject of anaesthetic mortality has been a source of considerable debate and discussion ${ }^{15}$. Post-operative complications related to the musculoskeletal system (fractures and post-anaesthetic myopathy) are more common in the horse than any other commonly anaesthetised animal and have been attributed to the size of the horse and its unique cardiopulmonary physiology as a highly evolved athletic animal ${ }^{7,10,15,19}$. Peri-anaesthetic mortality of about $1.9 \%$ has been reported when emergency abdominal cases are included in the surveys and about $0.1-1.0 \%$ when only elective surgical cases are considered $^{6,13,15,16,18,20}$. Furthermore, approximately one quarter of anaesthesia-related deaths may be due to fractures occurring during recovery ${ }^{17,19}$. There seems to be quite a wide discrepancy in equine anaesthesia-related mortalities from different studies, with a recent publication based on data from one private practice revealing rates as low as $0.21 \%^{2}$.

A number of measures can be used to minimise the risk of fractures in horses during recovery from anaesthesia. The horse can be given a central nervous system depressing drug, usually an alpha-2

a Department of Companion Animal Clinical Studies, Faculty of Veterinary Science, University of Pretoria, Private Bag X04, Ondesterpoort, 0110 South Africa.

*Author for correspondence.

E-mail: brighton.dzikiti@up.ac.za

Received: January 2008. Accepted: August 2008. adrenergic agonist, to calm it down while it recovers. This form of intervention tends to prolong the duration of the recovery period $^{13,19}$. Over the past few years, a number of sophisticated recovery systems such as the Anderson 'airlift' sling, the pool raft system and a rapidly inflatingdeflating air mattress have been developed $^{20,23}$. Simpler approaches like the use of ropes to steady the head and tail and use of experienced personnel within a well-padded stall to assist the horse are also employed ${ }^{22,23}$.

While published retrospective anaesthetic mortality prevalence data due to fractures exist in abundance, there is little information on reports of how individual cases occur.

\section{CASE HISTORY}

A 10 year-old Thoroughbred mare weighing $435 \mathrm{~kg}$ was presented to the Onderstepoort Veterinary Academic Hospital for weight-bearing lameness of the left hindlimb with mild swelling around the fetlock. The leg had been swollen and non-responsive to medical treatment for 5 months.

Physical examination of the horse confirmed the swollen left fetlock and tentatively diagnosed a proximal sesamoid bone chip fracture. The horse was in good body condition, had normal vital signs as well as normal body temperature, pulse rate and respiratory rate. Results of preoperative haematology profiling were within normal ranges except for the thrombocyte count, which was $127 \times 10^{9}$ per litre (normal range: $200-600 \times 10^{9}$ per litre). Radiography revealed a chronic apical fracture of the lateral proximal sesamoid bone of the left hindlimb with signs of early degenerative joint disease of the fetlock. Ultrasonography revealed mild chronic interosseous medius branch desmitis and confirmed the presence of the apical chip fracture observed on radiograph. Two bone fragments measuring $7 \mathrm{~mm}$ and $10 \mathrm{~mm}$ in diameter were removed arthroscopically from the left fetlock joint under general anaesthesia (anaesthetic procedure described below). Preoperatively the horse received phenylbutazone (Equipalazone ${ }^{\circledR}$ Powder (Bute), Kyron Laboratories, Benrose, South Africa for Arnolds Veterinary Products, UK) at $2.2 \mathrm{mg} / \mathrm{kg}$ twice per os, procaine penicillin (Depocillin ${ }^{\circledR}$, Intervet SA, Isando, South Africa) at $22 \mathrm{mg} / \mathrm{kg}$ and $1 \mathrm{ml}$ tetanus toxoid (Tetanus, Onderstepoort Biological Products, Onderstepoort, South Africa).

\section{Anaesthetic procedure}

Sedation was achieved by administration of romifidine hydrochloride (Sedivet ${ }^{\circledR}$ $1.0 \%$, Boehringer Ingelheim, Randburg, South Africa) at a dose of $20 \mu \mathrm{g} / \mathrm{kg}$ intravenously 30 minutes prior to induction of general anaesthesia. After local infiltration of $2 \mathrm{ml}$ mepivacaine hydrochloride (Mepivacaine $\mathrm{HCl}^{\circledR} 2 \%$, Kyron Laboratories, Benrose, South Africa), a 12-gauge catheter (Intraflon ${ }^{\circledR}$, Vygon Laboratories, Ecouen, France) was placed asceptically into the left jugular vein for administration of drugs and fluids peri-operatively. Glyceryl guaiacol ether (GGE Powder $100 \%$, Kyron Laboratories, Benrose, South Africa) which had been dissolved in sterile water (Intra-Pour Sterile ${ }^{\circledR}$, Fresenius Kabi, Bodene, trading as Intramed, Port Elizabeth, South Africa) to a $5 \%$ solution was administered at a dose of $50 \mathrm{mg} /$ $\mathrm{kg}$ intravenously for muscle relaxation, just before ketamine hydrochloride (Anaket $-\mathrm{V}^{\circledR} 10 \%$, Centaur Laboratories, Isando, South Africa) at a dose of $2.2 \mathrm{mg} /$ $\mathrm{kg}$ was administered for induction of general anaesthesia. The mare was endo- 
tracheally intubated using a $26 \mathrm{~mm}$ internal diameter cuffed silicone endotracheal tube (Bivona Incorporated, Indiana, USA). General anaesthesia was maintained with halothane (Halothane - M \& $\mathrm{B}^{\circledast}$, Safeline Pharmaceuticals Pty Ltd, Florida, South Africa) using a Tec 3 vaporiser (Fluotec $3^{\circledR}$, BOC Health Care, West Yorkshire, England). The halothane was delivered in oxygen via a large animal anaesthesia machine (Vet-Tec LAVC$2000^{\circledast}$, JD Medical Distributing Inc., Phoenix, USA). Intermittent positive pressure ventilation was instituted immediately after induction of general anaesthesia, aiming to maintain end-tidal carbon dioxide tension between 35 and $45 \mathrm{~mm} \mathrm{Hg}$. The horse was hoisted from the induction stall into the operating theatre. It was positioned on a well-padded operating table in dorsal recumbency with the forelimbs maintained in a semi-extended positioned by holding them up with the hoist, while the hindlimbs were unsupported in semi-extended position. Butorphanol tartrate (Torbugesic ${ }^{\circledR}$, Fort Dodge Animal Health, Fort Dodge, USA) at a dose of $40 \mu \mathrm{g} / \mathrm{kg}$ was administered intravenously for analgesia about 15 minutes after induction of general anaesthesia. Perineural block of the tibial nerve was performed by injecting $5 \mathrm{ml}$ of mepivacaine hydrochloride $2 \%$ medially into the groove between the gastrocnemius and the deep digital flexor tendons, while the peroneal nerve was desensitised by injecting $5 \mathrm{~m} l$ mepivacaine hydrochloride $2 \%$ into the groove between the tendons of the long and lateral digital extensors about $10 \mathrm{~cm}$ proximal to the lateral malleolus of the tibia. An intravenous crystalloid (Sabax Plasma Vet ${ }^{\circledR}$, Adcock Ingram Critical Care Ltd, Johannesburg, South Africa) was administered throughout the anaesthetic period at a rate of approximately $6 \mathrm{~m} / \mathrm{kg} / \mathrm{h}$. A 20-gauge catheter (Jelco ${ }^{\circledR}$, Medex Medical, Rosendale, Great Britain) was placed into the facial artery for direct arterial blood pressure measurements using a transducer (Manda Medical Systems, Bryanston, South Africa). An intravenous infusion of dobutamine (Dobutamine-Fresenius ${ }^{\circledR}$, Fresenius Kabi, Bodene, trading as Intramed, Port Elizabeth, South Africa) was used at $2-10 \mu \mathrm{g} / \mathrm{kg} / \mathrm{min}$ to maintain systolic arterial blood pressure above $90 \mathrm{mmHg}$ and mean arterial blood pressure above $70 \mathrm{mmHg}$. Monitoring devices such as a pulse-oximeter, an electrocardiogram, a direct arterial blood pressure measurement line, a temperature probe and a respiratory gas analyser were connected to the patient and read from a multi-parameter monitor (Cardiocarp $/ 5^{\circledR}$, Datex-Ohmeda Instrumentation Corpo-

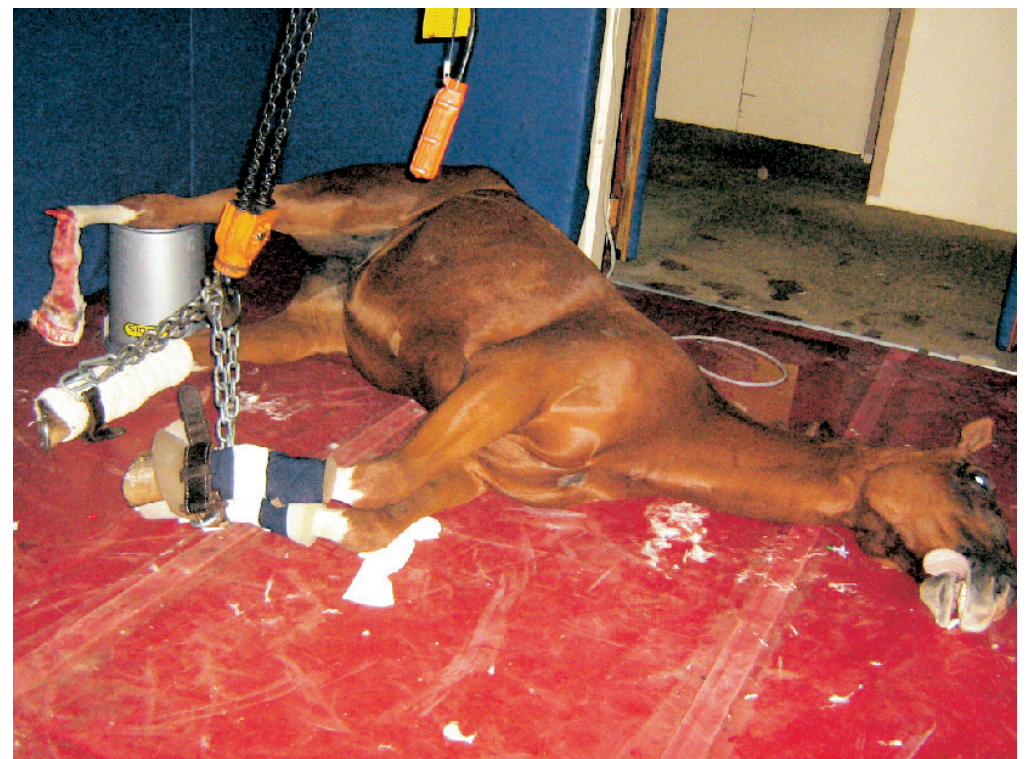

Fig. 1: Euthanased horse in the recovery room with the open fracture of the right metatarsal bones clearly visible.

ration, Helsinki, Finland).

The vital parameters monitored intraoperatively were stable throughout. Mean arterial blood pressure was maintained between $71 \mathrm{mmHg}$ and $82 \mathrm{mmHg}$ by intermittent administration of dobutamine. With respiratory rate set at 6 per minute and target maximum intra-thoracic pressure at $20 \mathrm{~cm} \mathrm{H}_{2} \mathrm{O}$ on the mechanical ventilator, the end-tidal carbon dioxide tension ranged from $38-44 \mathrm{mmHg}$. The period of general anaesthesia was $1 \mathrm{~h}$ $30 \mathrm{~min}$, while surgery lasted $45 \mathrm{~min}$. Before the horse was hoisted back to the recovery stall, $0.5 \mathrm{~m}$ lof romifidine hydrochloride $10 \mathrm{mg} / \mathrm{m} \ell$ was administered intravenously for sedation during the recovery period, and a Robert-Jones bandage covering parts distal to the tibio-tarsal joint was applied on the left (operated) hindlimb.

In the recovery stall, the horse was positioned in right lateral recumbency with the dependent forelimb stretched as far forwards as possible to reduce pressure on the radial nerve. The endotracheal tube was removed and a smaller nasopharyngeal tube placed to keep a patent airway. Oxygen was insufflated through a delivery tube directed into the vacant nostril at 12.0 /minute to provide supplemental oxygenation to the recumbent horse. A head support rope attached to a halter and controlled from outside the recovery box was used to assist the horse to stand during recovery from anaesthesia. The recovery box measuring $4.3 \mathrm{~m}$ in length and $3.0 \mathrm{~m}$ in width has a completely rubber-padded floor. The wall is about $4 \mathrm{~m}$ in height, is foam-padded up to a level of $1.9 \mathrm{~m}$. The lights were dimmed to minimise stimulation of the horse. The horse positioned itself in sternal recum- bency $15 \mathrm{~min}$ after termination of halothane and prematurely tried to regain standing position. It made its first attempt to stand with the right hind fetlock joint over-flexed, which meant that it was bearing full weight on the dorsum of the hoof and pastern region. The right metatarsus fractured within seconds of the horse bearing weight in this abnormal position. The horse managed to regain a standing position, but without bearing weight on the fractured limb.

The horse was quickly re-anaesthetised using diazepam (Pax ${ }^{\circledR}$, Pharmacare Limited, Port Elizabeth, South Africa) at a dose of $0.1 \mathrm{mg} / \mathrm{kg}$, butorphanol tartrate at a dose of $20 \mu \mathrm{g} / \mathrm{kg}$ and ketamine hydrochloride at a dose of $2.2 \mathrm{mg} / \mathrm{kg}$ intravenously and general anaesthesia was again maintained with halothane. Radiography showed an acute, open, oblique and comminuted displaced fracture of right third metatarsus extending from proximo-medially to disto-laterally as well as mildly displaced fractures of the right second and 4th metatarsi. The owner reluctantly opted for euthanasia as the fracture was of such a nature that it carried a poor prognosis. The horse was euthanased using $100 \mathrm{ml}$ of sodium pentobarbitone (Euthapent ${ }^{\circledR}, 20 \%$, Kyron Laboratories, Benrose, South Africa) administered intravenously (Fig. 1). Unfortunately, a post mortem examination on the horse was not performed as the owner did not consent.

\section{DISCUSSION}

Significant improvements in drugs, techniques and equipment for anaesthesia have been made over the past 100 years. However, deaths, disasters and minor mishaps continue to occur during the 
anaesthetic period ${ }^{8}$. In equine practice, where anaesthesia-related mortalities are substantially higher than in small animal practice, fractures (accounting for about a quarter of the mortalities) come second to cardiac arrests among the major causes of anaesthetia-related deaths ${ }^{2,3,14,20}$. Unfortunately, these fractures occur mostly during the recovery phase of anaesthesia, a critical phase indeed, but one which in many ways is the least controllable $e^{4,13,14,17}$. Recovery from general anaesthesia in the horse is not always a predictable event, since it is influenced by multiple factors such as surgical procedure, duration of anaesthesia, anaesthetic drugs, breed and age of the horse, assistance during recovery and pain ${ }^{6,25}$.

Horses are mostly euthanased as a result of re-fracturing along a recently repaired fracture line, unlike in this case where the contra-lateral leg was involved. We learn from this case that there is always a real danger of a horse fracturing any limb during anaesthesia, especially with orthopaedic surgical intervention ${ }^{26}$. In 2007, Bidwell and colleagues reported anaesthetic-related mortality in horses following arthroscopy to be as low as 6 out of 10000 , suggesting that the fracture suffered by the horse under discussion here is highly unlikely to be directly linked to the procedure for which the horse had been anaesthetised ${ }^{2}$. We suspect that the horse fractured the leg as a result of bearing excessive weight on the sound leg whilst avoiding bearing weight on the operated limb. The fact that excessive weight was placed on the right hind-limb while it was over-flexed on the fetlock joint may have increased the chances of the horse fracturing this leg. Peri-neural analgesia of the tibial and peroneal nerves, performed on the operated limb to provide additional analgesia, could have resulted in mild loss of proprioceptive function in that limb, which may then have compromised limb coordination as the horse attempted to stand. Although local anaesthetics block pain perception, they also impair proprioception, which inhibits the ability of a horse to determine location and orientation of the blocked area $^{11}$. It is also possible that 1 of the bones that fractured at recovery had a microfracture or stress fracture prior to anaesthesia and therefore could have failed to withstand the extra stress induced by the horse attempting to stand in an uncoordinated manner. A retrospective study on equine perioperative fatalities reported that thoroughbred mares aged above 9 years, as in this case, are more susceptible to fractures, especially of the tibia, during recovery, and this could be attributed to poor bone strength associated with old, non-active, multi-parturient broodmares $^{2,9,12}$.

The horse's 'flight behaviour', which prompts premature and violent recovery from anaesthesia, could be one of the reasons why horses panic as they regain consciousness from anaesthesia and suffer such injuries as fractured limbs and necks ${ }^{2,4}$. Ideally, horses regain consciousness within 1-20 minutes of anaesthetic agent discontinuation, roll to sternal position for a brief period and then rise ${ }^{13}$. The fact that the horse tried to stand prematurely without staying in sternal position for a while could be an indication of a temperament leaning towards high excitability. A conscious healthy horse usually never lies in dorsal recumbency, but sometimes spends short periods lying in lateral recumbency ${ }^{7,20}$. A wide variety of recovery protocols intended to assist the horse during awakening from general anaesthesia have evolved over time ${ }^{23}$. Interventions that can be used to minimise the occurrence of excitement during recovery of a horse from anaesthesia include head and tail support using ropes and administration of sedatives just before the horse is taken to the recovery area. These 2 approaches were not enough to prevent the horse in this case from fracturing its limb. Drugs that can be administered during the pre-recovery phase to render the horse calm include alpha-2 adrenergic agonists (romifidine $8 \mu \mathrm{g} / \mathrm{kg}$, detomidine $2-4 \mu \mathrm{g} / \mathrm{kg}$, xylazine $0.1-0.2$ $\mathrm{mg} / \mathrm{kg}$, medetomidine $1-2 \mu \mathrm{g} / \mathrm{kg}$ ), acepromazine $5-15 \mu \mathrm{g} / \mathrm{kg}$ and propofol $2 \mathrm{mg} /$ $\mathrm{kg}^{5,21}$. Sedatives administered during the pre-recovery phase are used to prolong the recovery time as it is well recognised that horses that take longer to stand often have smoother and more controlled recoveries from general anaesthesia. The time a horse takes to rise is often considered a temperament-dependent occurrence, and keeping the horse sedated and quiet may help decrease the rapidity with which it recovers ${ }^{17}$.

Providing optimum analgesia for the horse is known to improve quality of recovery by decreasing recovery time, decreasing physiologic stress and providing comfort during the post-operative period ${ }^{24}$. Drugs commonly administered for post-operative analgesia include butorphanol at $0.05-0.1 \mathrm{mg} / \mathrm{kg}$ and non-steroidal anti-inflammatory drugs like flunixine meglumine at $1.1 \mathrm{mg} / \mathrm{kg}$, phenylbutazone at $4.4 \mathrm{mg} / \mathrm{kg}$ and ketoprofen at $2.2 \mathrm{mg} / \mathrm{kg}^{1,24}$. Horses may be stressed during recovery due to a full bladder. It is therefore advisable to catheterise and drain the bladder before taking a horse to the recovery area, especially after long surgical procedures ${ }^{24}$. If a horse suffers a fracture while recovering from anaesthesia, it is advisable to induce general anaesthesia again, as well as provide adequate analgesia and physical support of the fractured limb for the welfare of the horse while a decision is being made on management of the fracture, because fractures are extremely painful and can cause severe distress ${ }^{16}$.

Techniques that can be employed for assisted recovery of the horse include use of experienced personnel within the recovery box, head and tail support, deflating air-mattress, vertical lifts or slings (Becker sling/lift, UC Davis lift, Anderson sling, Liftex sling) or pool systems like the Hydro-pool and Pool-raft systems ${ }^{5,6,22}$. However, each recovery method has its advantages and disadvantages and none is suitable for every situation ${ }^{4}$. Having people within a recovery box while a horse is recovering can be potentially dangerous to the attendants involved ${ }^{5,6}$. While the head and tail rope recovery technique offers better protection to the attendants, there is always a chance that the ropes might be lost after knot fait ure $^{5,6,22}$. The sling and pool recovery systems, which have been developed with the sopecific aim of reducing risk of fractures after orthopaedic surgery, are expensive to set up and maintain and also require well trained personnel $l^{5,22,25}$.

The overall anaesthesia-related mortality rate in equine anaesthesia of about $1 \%$ is still substantially high and thus equine practitioners are encouraged to be ever vigilant and anticipatory in order to be better prepared to manage mishaps if and when they occur. In retrospect, the accident reported here might have been avoided had the peri-neural analgesia of the tibial and peroneal nerves, which likely caused reduced proprioceptive function of the operated limb and then resulted in compromised limb coordination as the horse attempted to stand, not been performed.

\section{ACKNOWLEDGEMENTS}

The input of the nursing staff, support staff as well as final year veterinary and nursing students at the Onderstepoort Veterinary Academic Hospital who were involved in the management of this horse during the period of hospitalisation is greatly appreciated.

\section{REFERENCES}

1. Baller L S, Hendrickson D A 2002 Management of equine orthopaedic pain. Veterinary Clinics of North America. Equine Practice 18: 117-131

2. Bidwell L A, Bramlage L R, Rood W A 2007 Equine perioperative fatalities associated with general anaesthesia at a private practice - A restrospective case series. Veterinary Anaesthesia and Analgesia 34: 23-30 
3. Brodbelt D C 2006 The confidential enquiry into perioperative small animal fatalities. $\mathrm{PhD}$ thesis, University of London

4. Driessen B 2005 Assisted recovery in horses awakening from anaesthesia. In Steffey E P (eds) Recent advances in anaesthetic management of large domestic animals. International Veterinary Information Services, Ithaca. Online at: http://www.ivis.org/advances/ Steffey_Anesthesia/driessen3/chapter.asp? $\mathrm{LA}=\mathrm{A} 0619.0505$

5. Driessen B 2006 Assisted recovery. In Doherty T J, Valverde A (eds) Manual of equine anesthesia and analgesia (1st edn). Blackwell Publishing, Iowa: 338-351

6. Duke T 2006 Preoperative evaluation. The risk of equine anesthesia. In Doherty $\mathrm{T} \mathrm{J}$, Valverde A (eds) Manual of equine anesthesia and analgesia (1st edn). Blackwell Publishing, Iowa: 1-2

7. Edner A 2005 Effects of anaesthesia on haemodynamics and metabolism in horses: evaluated by laser Doppler flowmetry, microdialysis and muscle biopsy techniques. PhD thesis, Swedish University of Agricultural Sciences, Uppsala

8. Forsyth S 2007 Disaster avoidance: how to minimise adverse anaesthetic outcomes. Proceedings of the 32nd World Small Animal Veterinary Association Congress, Sydney, Australia, 19-23 August, 2007. Online at: http://www.ivis.org/proceedings/wsava/ 2007pdf/69_2007040614530_abs.pdf

9. Glade MJ 1993 Effects of gestation, lactation an calcium intake on mechanical strength of equine bone. Journal of the American College of Nutrition 12: 372-377

10. Hall L W, Clarke K W, Trim C M 2001 Veteri- nary anaesthesia (10th edn). W B Saunders. Harcourt Publishers, London

11. Harkins J D, Tobin T 1999 Lack of local anaesthetic efficacy of fentanyl in the abaxial sesamoid block model. Journal of Veterinary Pharmacology and Therapeutics 22: $52-55$

12. Hiney K M, Nielsen B D, Rosenstein D 2004 Short-duration exercise and confinement alters bone mineral content and shape in weanling horses. Journal of Animal Science 82: 2313-2320

13. Hubbell J A E 2007 Horses. In Tranquilli W J, Thurmon J C, Grimm K A (eds) Lumb and Jones' veterinary anaesthesia and analgesia (4th edn). Blackwell Publishing, Iowa: 717-729

14. Johnston G H, Eastment J K, Wood J L N, Taylor P M 2002 The confidential enquiry into perioperative equine fatalities (CEPEF): mortality results of phases 1 and 2. Veterinary Anaesthesia and Analgesia 29: 159-170

15. Jones R S 2001 Editorial: Comparative mortality in anaesthesia. British Journal of Anaesthesia 87: 813-815

16. Joubert K E, Duncan N, Murray N E 2005 Post-anaesthetic myelomalacia in a horse. Journal of the South African Veterinary Association 76: 36-39

17. Ko J C H 2002 Anaesthesia case of the month. Journal of the American Veterinary Medical Association 221: 790-792

18. Moens Y P S 2007 Anaesthesia of the foal. Proceedings of 40th European Veterinary Conference (Voorjarsdagen), Amsterdam, the Netherlands, 27-29 April 2007: 231-232

19. Murrell J C 2007 Evidence-based decision making in anaesthesia. Proceedings of 40th European Veterinary Conference (Voorjars- dagen), Amsterdam, the Netherlands, 27-29 April 2007: 232-233

20. Ray-Miller W M, Hodgson D S, McMurphy R M, Chapman P L 2006 Comparison of recoveries from anaesthesia of horses placed on a rapidly inflating-deflating air pillow or flow of a padded stall. Journal of the American Veterinary Medical Association 229: 711-716

21. Ringer S K, Kalchofner K, Bollar J, Furst A, Bettschart-Wolfensberger R 2007 A clinical comparison of two anaesthetic protocols using lidocaine or medetomidine in horses. Veterinary Anaesthesia and Analgesia 34: 257-268

22. Schaer T P, Bramage L R, Embertson R M, Hance S 2001 Proximal interphalangeal arthrodesis in 22 horses. Equine Veterinary Journal 33: 360-365

23. Sullivan E K, Klein L V, Richardson D W, Ross M W, Orsini J A, Nunamaker D M 2002 Use of a pool-raft system for recovery of horses from general anaesthesia: 393 horses (1984-2000). Journal of the American Veterinary Medical Association 221: 1014-1018

24. Taylor P M, Clarke K W 2006 Handbook of equine anaesthesia (2nd edn). W B Saunders Publishers, London

25. Valverde A, Gunkel C, Doherty T J, Pollak A S 2005 Effect of a constant rate infusion of lidocaine on quality of recovery from sevoflurane or isoflurane general anaesthesia in horses. Equine Veterinary Journal 37: 559-564

26. Zert Z, Mezerova J, Kabes R, Krisova S 2007 Sagittal fracture of the proximal phalanx in a horse complicated during induction of anaesthesia by complete fragmentation of the bone: a case report. Veterinarni Medicina 52: 79-82 